\title{
Online Search Strategies Of Educational Administrators For Determining The Credibility Of Information Gleaned From A Website
}

\author{
James L. Morrison, (Email: jlm@udel.edu), University of Delaware \\ Ganiyu T. Oladunjoye, (Email: lawaladisa@aol.com), Albany State University
} Dale Rose, Albany State University

\begin{abstract}
Based on a survey of 158 educational leaders situated in public schools, the level of educational leadership, whether a school superintendent or a principal in a secondary, middle-school, or elementary school, was not a significant factor in operational online strategies utilized or benchmarks relied upon for determining the credibility of information obtained from a website.
\end{abstract}

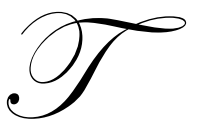

he No Child Left Behind legislation, directed from the Federal level, has resulted in the need for educational leaders to access credible data for making crucial decisions in regards to what is working and what is not in terms of student learning. In this regard, the reporting in the literature on effective and successful schools by educational leaders provides a rich source of data for those seeking solutions to instructional deficiencies in local school districts. In order to respond to questions of assessment about current curricula and instructional methodology, educational leaders are continuously searching for credible data sources about alternatives for addressing the issues that surround attempts to improve student performance in their schools.

The World Wide Web offers information and data from all over the world. Because so much information is available, and because information can easily be generated from 'anonymous sources,' it is necessary to develop skills to assess what is found. When using sources from an academic library, the books, journals and other resources have typically been evaluated by scholars, publishers and librarians. Such resources, therefore, have been subjected to some degree of scrutiny, in one way or another, before they are made available to the public. However, when accessing sites on the World Wide Web, none of this applies. There are few, if any, 'information filters.' Because anyone can write a Web page, or set up a 'blog,' documents of the widest range of quality, written by authors of the widest range of authority, are readily available. Excellent resources reside along side the most dubious.

\section{LITERATURE REVIEW}

The Web is of particular interest to professors and educational leaders who are generating research related to instructional effectiveness. In our colleges and universities across the county, courses in research methodology are typically included as one of those core courses required of educational majors in both graduate and undergraduate education programs. These courses often contain an orientation to the library where students learn to access an ever-growing number of electronic data sources. Kurland (1996) argues that the ease and attractiveness of using the Web "links browsing the Web to rummaging through the worlds academic, governmental, commercial and entertainment attics" (p. 134). Therefore, students, faculty, and other educational leaders can waste valuable time searching for information on the Web because it lacks a comprehensive catalog that classifies materials by reliability and validity criteria. In addition, new resources can be added voluntarily everyday (Harris, 1996). 


\section{A Growing Reliance Upon The Web}

Due to its easy access, the Web is becoming a primary source for both timely and low-cost information. In this regard, over the past decade, the number of computers located in both the offices of educational administrators schools and in the classroom has increased exponentially. (Baboolal, 2005) However, a school's vision of the education it strives to provide contains many elements, of which technology is but one. Other elements in this vision include administrative policies, curricula, classroom organization, teachers' pedagogical approaches, space utilization, school-community partnerships and other logistical factors. Developing ways to take advantage of available technology to advance decision-making through the access of credible information is one of the most challenging issues facing educational administrators today.

To analyze leadership practices, data must be gathered that is timely, relevant, and accurate. This process involves gaining access to data on how school leaders define, present, and carry out assessment policies. Time management is a significant parameter in this process. Collecting data is what school leaders do. Data is required to justify the moves educational leaders make and how they execute tasks. Being deficient in data can lead to misguided work practices, waste of financial resources, and frustrated teachers (Wellman, 1995, cited in Suchman, 1995). Not gaining access to appropriate data particularly hinders school leadership at the upper levels where setting school priorities sets the stage for engagement by others. (Hallinger \& Heck, 1998; Heck \& Hallinger, 1999). In this regard, Eccles \& Nohria (1992) argue that data access is now more crucial than ever since the pace of change has accelerated the need to make decisions within shorter time constraints.

As recent as five years ago, Web users were being advised to gauge Web site credibility by examining author credential and expertise. For example, Kirk (1996) suggested that there are five critical factors that should be part of the decision-making criteria for determining whether data accessed on the Web is credible. The first and most important is authorship, specifically the reputation of the individual who has published the data. The next factor is the publishing organization, and in particular how materials are screened in order to verify that they meet the standards of clarity and truthfulness. This may include peer review. Thirdly, point of view (or bias) is a factor that reflects the likelihood that information on the Web is rarely neutral. Because data is used in selective ways to form information, it generally represents a point of view. The popularity of the Internet makes it the perfect venue for commercial and socio-political publishing. Because the structure of the Internet allows for easy self-publication, information bias must be identified quickly before relying upon it use during decision-making. A fourth factor in the criteria section is knowledge of the literature, referring to the context in which the author publishes his or her work. This reveals what the author knows about his or her discipline and its practices. A fifth factor Kirk suggests as significant is currency, referring to the timeliness of information. In printed documents, the date of publication is the first indicator of currency.

Even though there is a wide variety of information available on the Web, making it one of the most powerful tools for doing research, there is some evidence that users may be abandoning recommended criteria for screening sites accessed during data searches. (Pearson, 2005) Recent research shows that users may be moving away from simply relying on author's credentials, etc., by instead relying on a combination of other factors such as Webpage appearance, ease to move about a site, and usefulness of information. (Glickman, Gordon \& Ross-Gordon, 2004)

\section{Decentralizing Planning And Designing Changes In Education}

Among the solutions being offered to improve the quality of America's public schools is decentralizing decision-making authority from state educational agencies to local school districts, and in particular, to local school sites. The shift is being recommended in the belief that organizations will perform better if those who implement changes in instructional programs have a greater say in decision making. (Hallinger, P. \&Heck, R., 1998) This process parallels a similar movement in the private sector today. In this regard, the need for credible information for planning, designing and implementing change is now paramount to leaders in most organizations and especially in education for superintendents of local school districts and for principals of schools. 
Increasing both principal and classroom teacher involvement at the local level in school decision making is highly ranked among the most promising educational reform strategies. (Baboolal, M, 2005) However, findings from research reveal that teachers often vary in their willingness to participate in varying levels of decisions. Baboolal argues that the creation of teacher-principal working relationships exert the greatest single influence on a willingness to participate across decision areas. Baboolal's findings also suggest that accessing and distributing data to all those involved in school planning is an extremely vital aspect of implementing successful strategies for improving educational programs.

With a significant importance attached to accessing and disseminating data to those who are engaged in enhancing educational opportunities for students, this connection is vital for generating effective changes in education.. (Asayesh, 1993). With educational administrators working closely with classroom teachers during the design phases, gaining access to credible data quickly has become a priority. (Guskey, 1991, 1994; Sparks, 1994, 1996a). Both faculty and administrative development relies upon being current as to what is occurring in education nationwide. (Guskey \& Sparks, 1991). Information collection and dissemination are now identified as key factors that affect educational improvement. (Guskey, 1995; Sparks, 1995a, 1995b). In this regard, therefore, it is argued here that educational leaders, like many others, typically search the Web for reliable and valid information through trial and error encounters. Since there is no one way to search and access data electronically, this presents an intriguing area for study. Analyzing leadership information search practices begins with an understanding of how educational data is gathered and verified as credible.

\section{STATEMENT OF THE PROBLEM}

Accuracy or verifiability of details is an important part of the evaluation process, especially when reading the work of an unfamiliar author presented by an unfamiliar organization. In a formal research document produced in the past, the data that was gathered is typically documented as to source and time. Also included is an explanation of the research method(s) used to gather and interpret that data. The methodology outlined in the document generally allows the study to be duplicated by others for purposes of verification. A typically written document relies on external sources that are typically listed in a bibliography (or found in 'web-links' to the documents themselves). As noted here, it has been critical in the past for educational leaders to verify that information obtained is both factual and timely before it use in any decision-making process.

Similarly, today, in regards to information obtained from the Web, the effectiveness of educational leaders often depends upon accessing credible data to provide answers to the following questions: What improvements in student learning do we seek and what changes must be made to get those results? What types of staff and faculty development are required to make those improvements? How will we know if faculty development led to those improvements? Questions such as these have perplexed researchers and educational leaders for years. Answering these questions, however, is even more pressing today. Policymakers consistently note the need for substantive, high quality data, and it is argued here that the Web is becoming a primary resource for educational leaders seeking alternatives to resolve current issues in curricula and instruction. Therefore, the hypothesis tested in this study is:

1. The online strategies utilized by educational leaders in public schools for determining the credibility of information accessed from the WEB will not vary by leadership position (job level), frequency of use, or information search skill level.

\section{RESEARCH METHODOLOGY}

Written questionnaires were mailed to each of 500 educational leaders situated in the public schools during November of 2005. The study population was derived from a random sample of a database established by LIST, a list brokerage and management company situated in Lake Success, NY. In this study, an educational leader is defined as an individual who has the title of superintendent or principal in a secondary-school, middle-school, or elementary-school. One-hundred and sixty-three questionnaires were collected between November 15, 2005, and December 16, 2005. However, five survey instruments were deleted from the study due to illegible responses. 
Therefore, the research sample in this study included perceptions of 158 educational leaders in public education, representing 31.6 percent rate of return.

Respondents to a written survey were requested to indicate their perceptions of overall operational online information searching strategies used and the benchmarks they relied upon for determining source credibility. A 4point rating scale was utilized, with a 1 indicating an information search strategy was most often used and a 4, never used. The entire survey instrument consisted of 40 items. In addition, demographics were also collected as relating to gender, race, leadership title, frequency of Web access, and skill level for searching for information.

A one-way analysis of variance (GLM model) was performed on data collected with frequency of use, leadership title, and degree of perceived skill at using Boolean search commands being the independent variables. A .05 level of significance was used to accept or reject the hypothesis tested in the study.

\section{FINDINGS}

The sample of the study consisted primarily of male and female educational leaders who may be categorized as Caucasian. (See Table 1). Approximately two-thirds of the respondents to the written survey were employed as school principals $(\mathrm{n}=103)$ with the remaining 55 classified as school superintendents. In terms of degree of skill level in regards to searching for information, 32 respondents perceived they had considerable skill while 83 indicated minimal skill in conducting Web searches. In terms of frequency in using their personal computers to search for information, 98 respondents indicated they searched the Web daily and 18 at least once a week. Only 42 respondents indicated that they used their personal computers to a lesser degree for searching for information during the working day.

Table 1: Demographics of Sample $(\mathrm{N}=158)$

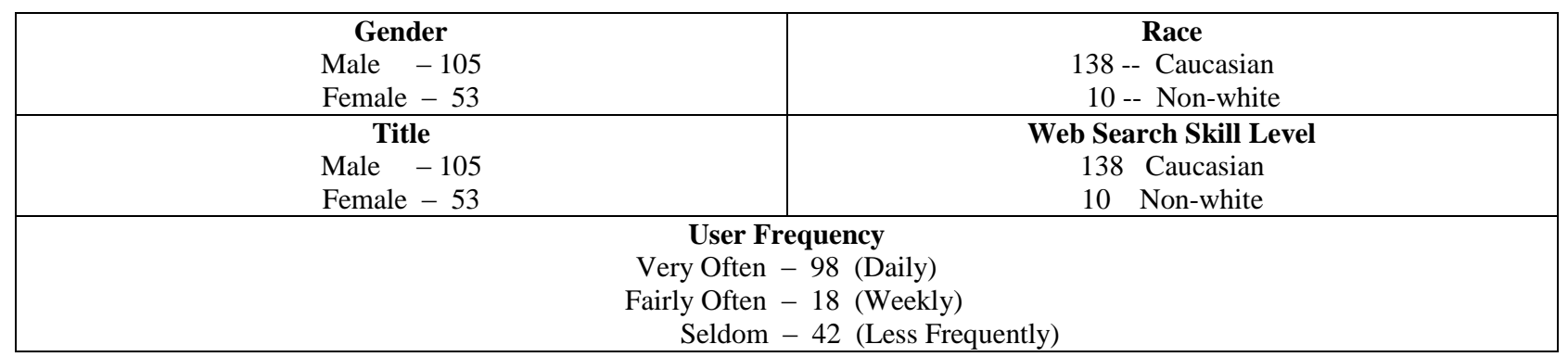

In terms of where educational leaders in the study sample got their information, the most frequent sources were professional journals and magazines. The Web was indicated as the second most likely source for information. Less likely sources indicated were the radio and designated research services (such as the Rand Institute, etc.) which often require a fee (See Table 2.)

Table 2: Means of Scores of Overall Source for Information (External) (N=158)

\begin{tabular}{lcc}
\hline Information Source & Mean Rating & Standard Deviation \\
\hline Journal/Magazines & 2.22 & 0.8363 \\
Web & 2.44 & 0.7093 \\
Newspaper & 2.67 & 0.7692 \\
Television Media & 2.93 & 0.8114 \\
Research Services & 3.01 & 0.9872 \\
Radio & 3.13 & 0.8225 \\
\hline Rating Scale: 1 1 = Most Often; 2= Frequently; & 3=Seldom; 4 = Never
\end{tabular}


In terms of overall operational strategies initiated by educational leaders in the study sample, the most frequent item reported was that of confirming information found before using it in decision-making. (m-2.42). (See Table 3). The least often strategy used was that of providing personal data onto the Web $(\mathrm{m}=3.64)$ and seeking information about a website tracking by means of using cookies $(\mathrm{m}=3.57)$. It was also revealed by these educational administrators that they only had moderate level of trust in those who author information onto a website. $(\mathrm{m}=2.63)$

Table 3: Mean Scores of Overall Operational Strategies $(\mathrm{N}=158)$

\begin{tabular}{llc}
\hline \multicolumn{1}{c}{ Strategy } & Mean & Standard Deviation \\
\hline Confirm Information Found & 2.42 & 0.8903 \\
Trust Website Authors & 2.63 & 0.5683 \\
Get Info. On Site Ownership & 3.22 & 0.8265 \\
Use Advance Boolean Commands & 3.25 & 0.9371 \\
Read Site Privacy Policy & 3.36 & 0.7246 \\
Seek Cookie Links & 3.57 & 0.7512 \\
Provide Personal Data & 3.64 & 0.5422 \\
\hline
\end{tabular}

Rating Scale: 1 = Most Often; 2-Frequently;3-Seldom;4- Never

When applying benchmarks for determining the credibility of information accessed on the Web, the educational leaders most often perceived website semantics $(\mathrm{m}=1.36)$, purpose of website $(\mathrm{m}=1.64)$; kind of organization publishing information $(\mathrm{m}=1.69)$ and reputation of the author $(\mathrm{m}=1.73)$ as most commonly used. To a smaller degree, site awards for quality $(\mathrm{m}=3.04)$ and site use of commercial advertising $(\mathrm{m}=2.85)$ were less utilized as benchmarks for quality recognition.. (See Table 4).

Table 4: Mean Scores of Website Benchmarks Influencing Information Credibility Decisions

\begin{tabular}{llc}
\hline \multicolumn{1}{c}{ Benchmark } & Mean & Standard Deviation \\
\hline Website Semantics & 1.36 & 0.6320 \\
Purpose of Website (commercial, academic)etc. & 1.64 & 0.6698 \\
Kind of Organization Publishing Info. & 1.69 & 0.6838 \\
Reputation of Author & 1.73 & 0.7086 \\
Quality of Documentation Included & 1.81 & 0.7610 \\
Reputation of Website & 1.85 & 0.7212 \\
Links to Verifiable Info. & 1.98 & 0.7110 \\
Year Info.. Published/Currency & 2.03 & 0.7351 \\
Referred by Another & 2.05 & 0.6980 \\
Website Security & 2.08 & 0.8438 \\
Copyright Status & 2.12 & 0.8548 \\
Often Website Updated & 2.16 & 0.7057 \\
Contact Info. Unclear & 2.42 & 0.7922 \\
Visual Design & 2.48 & 0.7795 \\
Authentication of Information & 2.74 & 0.7915 \\
Commercial Advertising Prominent & 2.85 & 0.9632 \\
Site Awards for Quality & 3.04 & 0.6989 \\
\hline
\end{tabular}

Rating Scale: 1 = Most Often; 2 = Frequently; 3 =Seldom; 4 - Never

Results of a one-way analysis of variance (GLM) statistical procedure reveals that those educational leaders who most often use the WEB for gathering information also most often confirm information found as a normal operational procedure $(\mathrm{M}=2.42)$ whereas those who search for information less often seldom do such checking $(\mathrm{M}=2.78)$ (See Table 5) In terms of degree of skilled held by the respondent, there were significant differences in the perception of operational procedures performed in regards to relying upon an external source to the WEB (such as a special research service), getting confirmation on quality of information accessed, seeking information about site ownership, and actually reading privacy policy of the site. Generally, those with the most competency in 
searching for information (Skill Levels $1 \& 2$ ) performed these tasks significantly more often while those with less competency (Skill Level $3 \& 4$ ) seldom performed such tasks. However, all users, no matter the level of information searching skills possessed, generally do not frequently read a website's privacy policy where the range of mean scores were from 2.57 to 3.58. (See Table 5.)

Table 5: Significance of Frequency of Online Searching and Skill Level Held to Web Operational Strategies (N=158)

\begin{tabular}{|c|c|c|c|c|c|c|}
\hline Credibility Issues & \multicolumn{4}{|c|}{ Means**** } & F Score & Prob.*** \\
\hline \multirow[t]{2}{*}{ By Frequency of Use -- } & \multicolumn{4}{|c|}{ Degree of Frequency* } & & \\
\hline & 1 & 2 & 3 & 4 & & \\
\hline Confirmation of Info. Found & 2.42 & 2.22 & 2.78 & 2.59 & 2.54 & .05 \\
\hline \multirow[t]{2}{*}{$\underline{\text { Search Skill Level -- }}$} & \multicolumn{4}{|c|}{ PC Search Skill Level ${ }^{* *}$} & & \\
\hline & 1 & 2 & 3 & 4 & & \\
\hline Research Services Utilized & 2.45 & 3.05 & 2.83 & 3.16 & 2.65 & .05 \\
\hline Information Confirmation & 1.91 & 2.04 & 2.37 & 2.91 & 3.83 & .01 \\
\hline Site Ownership & 2.71 & 2.91 & 2.93 & 3.61 & 7.87 & .00 \\
\hline Privacy Policy & 3.27 & 2.57 & 3.02 & 3.58 & 4.72 & .00 \\
\hline
\end{tabular}

$* 1=$ Most often; 2 = frequent; $3=$ seldom; $4=$ never

$* * 1=$ Most Competent $; 2=$ Somewhat Competent $; 3=$ Less Competent $; 4=$ Not Competent

****Mean Scores = 1-most often; 2 -frequently; 3- seldom; 4-never

***Statistical Measure: One-Way Analysis of Variance (Significance: $=$ or $<.05$ Level

Those with a perceived greater degree of Web information searching skills had significant differences in the frequency of use of specific benchmarks when determining the credibility of information obtained by electronic means. Generally, those with a greater degree of Web searching skill were more frequent users of such 'credibility' benchmarks as authentication of source, visual design of site, reputation of author, documentation quality, and quality of links to other sites. (See Table 6) In this instance, those educational leaders with high perceived search skills (Skill Level 1) had mean scores ranging from 1.18 to 2.45 while those with lesser degree of search skills (Skill Level 4) had mean score ranging from 2.01 to 3.10 .

Table 6: Significance of Frequency of Online Searching Skill Level Possessed to Web Operational Strategies (N=158)

\begin{tabular}{|c|c|c|c|c|c|c|}
\hline Benchmark & \multicolumn{4}{|c|}{ Means* $^{*}$} & \multirow[t]{3}{*}{ F Score*** } & \multirow[t]{3}{*}{ Prob. } \\
\hline \multicolumn{5}{|c|}{ (PC Search Skill Level)** $^{* *}$} & & \\
\hline & 1 & 2 & 3 & 4 & & \\
\hline Authentication of Source & 2.45 & 2.47 & 2.72 & 3.10 & 2.80 & .04 \\
\hline Visual Design & 2.32 & 2.19 & 2.39 & 2.94 & 2.79 & .04 \\
\hline Documentation Quality & 1.27 & 1.67 & 1.86 & 2.35 & 2.62 & .05 \\
\hline Reputation of Author & 1.18 & 1.66 & 1.79 & 2.01 & 2.71 & .04 \\
\hline Links to Verifiable Info. & 1.81 & 1.71 & 1.91 & 2.33 & 2.61 & .05 \\
\hline
\end{tabular}

$* 1=$ Most often $; 2$ = frequent $; 3=$ seldom; $4=$ never (Mean Scores)

$* * 1=$ Most Competent $; 2=$ Somewhat Competent $; 3=$ Less Competent $; 4=$ Not Competent

***Statistical Measure: One-Way Analysis of Variance (Significance: $=$ or $<. .05$ Level)

\section{CONCLUSIONS}

It may be concluded that the level of leadership (job title/position), whether a school district superintendent or a principal in a secondary, middle-school, or elementary school, was not a significant factor in operational online strategies utilized or benchmarks relied upon for determining the credibility of information obtained from a website. Similarly, with just one exception, frequency of conducting an online information search was not a significant factor in terms of the kinds of online operational strategies utilized by those in the sample of this study. 
However, the information search skill level of the personal computer user was a significant factor for four of the seven operational strategies included on the survey instrument. Specifically, those with a greater perceived skill for retrieving information from the WEB were more likely to utilize a research service external to the WEB for additional information, to seek another person's advice on information obtained from a website, and to determine who or what organization runs the website. Therefore, it may be concluded that educational leaders with a greater perceived skill for searching information do not generally trust the data obtained and rely upon either another person or an independent agency to assure the most useful information is obtained.

It may also be concluded that information search skill level is a significant factor when utilizing benchmarks for determining the credibility of information access from a website. Those with a greater perceived level of information search skills are more likely to rely on the benchmarks of authentication of source of information, website visual design, quality of actual documentation of information used on site, links to other quality websites, and reputation of the author than those with lesser perceived pc skills. Therefore, it may be that the perceptions of educational leaders do vary considerably according to their skill level, particularly in regards to determining the credibility of information obtained online.

Finally, based on the findings of this study, there maybe a need to upgrade the information search skills of educational leaders in terms of enhancing their capability to access credible information over the WEB. With the WEB indicated as the second most used source for retrieving information by the sample of the study, and with a vast majority of respondents indicating only some or minimal skill in searching for credible information by electronic means, there appears a need to devote more attention to assisting educational leaders to use the WEB more efficiently and with better results. Relying upon a 'trial and error' strategy for seeking out information may not be the best approach for gathering credible information. Identifying appropriate benchmarks along with seeking out information about the credibility of a website itself appear to be growing in importance as data availability grows exponentially from even day to day. Not being aware of readily identifiable benchmarks for judging credibility of information made available over the WEB or an inability to apply such benchmarks in a screening decision-making process can lead to disastrous results (proposals for change) for those leading educational reform.

\section{REFERENCES}

1. Asayesh, G. (1993). Staff development for improving student outcomes. Journal of Staff Development, 14(3), 24-27.

2. Baboolal, M. (2005). Educational Computer Systems - Support and Maintenance Jamaica Computer Society Education Foundation, ICT4D JAMAICA, http://www.itd4djamaica.org.

3. Eccles, R. G., \& Nohria, N. (1992). Beyond the hype: Rediscovering the essence of management. Boston: Harvard Business School Press.

4. Guskey, T. R. (1991). Enhancing the effectiveness of professional development programs. Journal of Educational and Psychological Consultation, 2(3), 239-247.

5. Guskey, T. R. (1995). Professional development in education: In search of the optimal mix. In T. R. Guskey \& M. Huberman (Eds.), Professional development education: New paradigms and practices (pp. 114-131). New York: Teachers College Press.

6. Hallinger, P., \& Heck, R. H. (1998). Exploring the principal's contribution to school effectiveness: 19801995. School Effectiveness and School Improvement, 9, 157-191

7. Harris, C. (1996). An internet education. Belmont, CA: Wadsworth Publishing.

8. Heck, R. H., \& Hallinger, P. (1999). Next generation methods for the study of leadership and school improvement. In J. Murphy \& K. Louis, Handbook of educational administration (pp. 141-162). New York: Longman.

9. Kurland, D. J. (1996). The net, the web, and you. Belmont, CA: Wadsworth Publishing.

10. Sparks, D. (1994). A paradigm shift in staff development. Journal of Staff Development, 15(4), 26-29.

11. Sparks, D. (1995a). Focusing staff development on improving student learning. In G. Cawelti (Ed.), Handbook of research on improving student achievement (pp. 163-169). Arlington, VA: Educational Research Service. 
12. Sparks, D. (1995b). Using research to improve staff development: An interview with Tom Guskey. Audiotape interview from the Leaders in Staff Development series. Oxford, OH: National Staff

Development Council.

13. Suchman, L. A. (1995). Representations of work. Communications of the ACM, 38(9), 56-64.

\section{NOTES}

